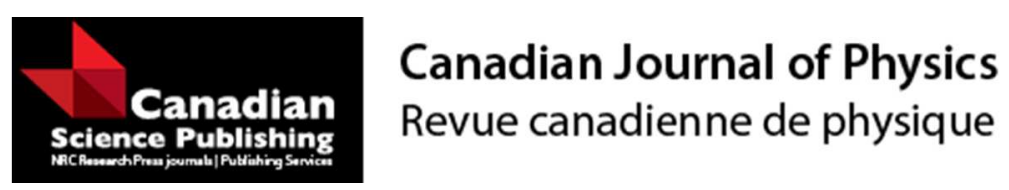

Nonlinear Rosseland thermal radiation and magnetic field Effects on flow and heat transfer over a moving surface with variable thickness in a Nanofluid

\begin{tabular}{|r|l|}
\hline Journal: & Canadian Journal of Physics \\
\hline Manuscript ID & cjp-2016-0345.R1 \\
\hline Manuscript Type: & Article \\
\hline Date Submitted by the Author: & $13-$ Oct-2016 \\
\hline Complete List of Authors: & Abdel-wahed, M.S.; Benha University \\
\hline Keyword: & $\begin{array}{l}\text { Nanofluids, variable thickness,, thermal radiation,, non-linear magnetic } \\
\text { field, heat transfer }\end{array}$ \\
\hline \multicolumn{2}{|l}{} \\
\hline
\end{tabular}




\title{
Nonlinear Rosseland thermal radiation and magnetic field Effects on flow and heat transfer over a moving surface with variable thickness in a Nanofluid
}

\author{
Mohamed S. Abdel-wahed \\ Basic Sciences Department, Faculty of Engineering at Benha, \\ Benha University, Cairo, Egypt. \\ E-mail: eng_moh_sayed@live.com
}

\begin{abstract}
A numerical investigation has been done to study the impact of nonlinear magnetic field, nonlinear thermal radiation, variable thickness, Brownian motion on flow and heat transfer characteristics (i.e. skin friction and surface heat flux) as a physical application. Moreover, the impact of these forces on the rate of cooling and the mechanical properties (i.e. hardness, ductility...) of the surface that cooled using Nanofluid as a coolant. The governing boundary layer equations describing the problem transformed to ordinary differential equations using similarity transformation method and then solved numerically using fourth order RungeKutta method with shooting technique by assistance of Mathematica program.
\end{abstract}

Key words: Nanofluids, variable thickness, non-linear thermal radiation, magnetic field.

\section{Introduction}

Study of boundary layer behavior over a moving surface is one of the most important problems due to their importance to the industry process such as paper production, plastic extrusion, fibers ... etc. This is not the only applications of the problem. Moreover, it considered as a mathematical simulation to the heat treatment processes of the metal surfaces that subjected to a rising in temperature and cooling to reach to the required mechanical properties.

The boundary layer flow caused by a moving surface has drawn the attention of many researches [1-13]. Through these papers, the researchers interested in some of external forces that acting on the boundary layer such as magnetic field, thermal radiation, heat generation, suction/injection process, and the unsteady motion. The concept of using a regular fluid for cooling has been changed after defining a new type of fluid called a Nanofluid by Choi [14].

Choi defined a new type of fluid consisting of suspended particles in Nano size within a regular fluid such as oil, water and ethylene glycol, these particles improve the thermal conductivity of the flow, which open a new and wide applications in the industry especially in the field of cooling and heat treatment process.

The behavior of the Nanofluid boundary layer over a moving surface has been investigated by A zizah et. al. [15] they studied the effect of unsteady motion of a shrinking sheet in presence of suction, Rana et al. [16] studied the effect of nonlinear velocity of a stretching sheet in nanofluids. Aminreza et al. [17] investigate the effect of partial slip boundary condition on the flow and heat transfer of nanofluids past a stretching surface with constant wall temperature. Hamad [18] present an analytical solution for natural convection flow of nanofluids with magnetic field. Yacob et al. [19] studied the effect of external uniform shear flow with convective surface boundary condition on a Nanofluid over a shrinking surface. Elbashbeshy et al. [20], [21] deduced an exact solution to the Nanofluid boundary layer problem over a moving surface in presence of magnetic field and suction/injection process for both cases 
steady and unsteady motion. The effect of heat generation on the thermal boundary layer of Nanofluid has been studied by Alsaedi et al. [22].

The effect of thermal radiation on the boundary of Nanofluid for a different cases has been investigated by Magyari et al. [23], Motsumi et al., [24] and Hady [25], Elbashbeshy et al. [26], Astrerios et al.[27], Mohyud-Din et al. [28], Khan et al., [29] and Abdel-wahed et al. [30] and [31].

It is worth mentioning that all pervious papers considered a uniform distribution of nanoparticles within the boundary layer. The effect of Brownian motion and thermophoresis on the Nanoparticles distribution within the boundary layer has been investigated by Anbuchezhian et al. [32] and Kandasamy et al. [33].

Since the variable thickness may occur in the engineering applications more frequently than a flat surface. Fang et al. [34], Elbashbeshy et al. [35], Abdel-wahed et al. [36] developed the study of the boundary layer problem by taking into consider the effect of the surface thickness variation on the boundary layer behavior in the presence of different forces.

The present work investigates the effect of nonlinear Rosseland thermal radiation and nonlinear magnetic field on the boundary layer behavior and the impact of these forces on the mechanical properties of a surface with variable thickness through the process of cooling.

\section{Formulation of the problem}

It is assumed that a surface with variable thickness $y=\delta(x+b)^{\frac{1-n}{2}}$ moving with nonlinear velocity $U_{w}(x)=a(x+b)^{n}$ within steady, laminar, incompressible cooling medium consists of nanoparticles and water base fluid. The fluid subjected to nonlinear transverse magnetic field with strength of $B(x)=B_{0}(x+b)^{\frac{n-1}{2}}$ and nonlinear thermal radiation with heat flux $\mathrm{q}_{\mathrm{r}}=-\left(\frac{4 \sigma^{*}}{3 \alpha^{*}}\right) \frac{\partial T^{4}}{\partial y}$.

Moreover, it is assumed that the surface is sufficiently thin with no induced stream-wise pressure gradients and the induced magnetic field produced by the motion of an electrically conducting fluid is negligible.

As shown in figure (1), the temperature of the surface assumed $T_{w}$ and the ambient temperature of the boundary layer taken $\mathrm{T}_{\infty}$.

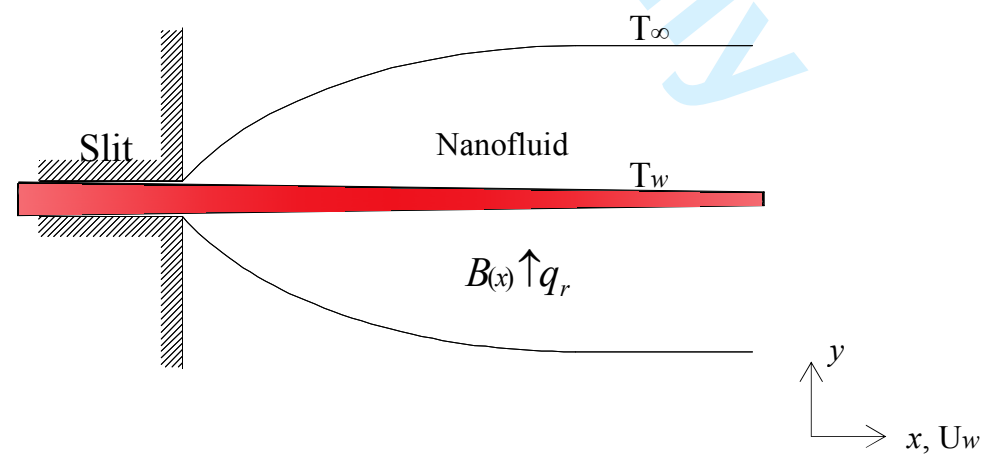

Fig. (1) Physical model and coordinate system.

The governing boundary layer equations describing the steady two-dimensional laminar hydromagnetic nanofluid flow over a moving surface and subjected nonlinear Rosseland thermal radiation can be written as: 


$$
\begin{aligned}
& \frac{\partial u}{\partial x}+\frac{\partial v}{\partial y}=0 \\
& u \frac{\partial u}{\partial x}+v \frac{\partial u}{\partial y}=v \frac{\partial^{2} u}{\partial y^{2}}-\frac{\sigma B^{2}(x)}{\rho} u \\
& u \frac{\partial T}{\partial x}+v \frac{\partial T}{\partial y}=\alpha^{\times} \frac{\partial^{2} T}{\partial y^{2}}+\tau\left[D_{B} \frac{\partial C}{\partial y} \frac{\partial T}{\partial y}+\frac{D_{T}}{T_{\infty}}\left(\frac{\partial T}{\partial y}\right)^{2}\right]+\left(\frac{4 \sigma^{*}}{3 \alpha^{*} \rho C p}\right) \frac{\partial^{2} T^{4}}{\partial y^{2}} \\
& u \frac{\partial C}{\partial x}+v \frac{\partial C}{\partial y}=D_{B} \frac{\partial^{2} C}{\partial y^{2}}+\frac{D_{T}}{T_{\infty}}\left(\frac{\partial^{2} T}{\partial y^{2}}\right)
\end{aligned}
$$

With boundary conditions

$$
\begin{aligned}
& u=U_{w}, \quad v=0, \quad T=T_{w}, \quad C=C_{w}, \quad \text { at } \quad y=\delta(x+b)^{\frac{l-n}{2}} \\
& u=0, \quad v=0, \quad T=T_{\infty}, \quad C=C_{\infty} \quad \text { as } y \rightarrow \infty
\end{aligned}
$$

Where $n$ is the shape parameter. It is assumed $n>-1$ in this work for the validity of the similarity variable and functions.

\section{Similarity Transformation}

Looking for similarity solution of equations (1-4) with the boundary conditions (5) using the following form

$$
\eta=y \sqrt{\left(\frac{n+1}{2}\right)\left(\frac{a(x+b)^{n-1}}{v}\right)}, \quad \psi=\sqrt{\left(\frac{2}{n+1}\right)(x+b)^{n+1} a v} F(\eta)
$$

Assuming the boundary layer temperature and Nanoparticles concentration take the form

$$
T=T \infty+[T w-T \infty] \theta(\eta) \text { and } C=C \infty+[C w-C \infty] \phi(\eta)
$$

where $\eta$ is the similarity variable, and $\psi$ is the stream function which is defined as $u=\frac{\partial \psi}{\partial y}$ and $v=-\frac{\partial \psi}{\partial x}$ which satisfies equation (1).

substituting by equations (6) into eqs. (2-4), one can obtain the following ordinary differential equations:

$$
\begin{aligned}
& F^{\prime \prime \prime}+F F^{\prime \prime}-\left(\frac{2 n}{n+1}\right) F^{\prime 2}-\left(\frac{2}{n+1}\right) M F^{\prime}=0 \\
& 3 \theta^{\prime \prime}+R_{d} \frac{\left[\left(1+\left(\theta_{w}-1\right) \theta\right)^{4}\right]^{\prime \prime}}{\left(\theta_{w}-1\right)}+3 \operatorname{Pr}\left[F \theta^{\prime}+N b \theta^{\prime} \phi^{\prime}+N t \theta^{\prime 2}\right]=0 \\
& \phi^{\prime \prime}+\frac{1}{2} \operatorname{Le} F \phi^{\prime}+\left(\frac{N t}{N b}\right) \theta^{\prime \prime}=0
\end{aligned}
$$

With boundary conditions

$$
F(\alpha)=\alpha\left(\frac{1-n}{1+n}\right), \quad F^{\prime}(\alpha)=1, \quad \theta(0)=1, \quad \phi(0)=1 \quad \text { and } \quad F^{\prime}(\infty)=0, \quad \theta(\infty)=0, \quad \phi(\infty)=0
$$


here primes denote differentiation with respect to $(\eta)$

by defining $F(\eta)=f(\eta-\alpha)=f(\zeta)$, Therefore the similartiy equations (8-10) and the associated boundary conditions (11) become

$$
\begin{aligned}
& f^{\prime \prime \prime}+f f^{\prime \prime}-\left(\frac{2 n}{n+1}\right) f^{\prime 2}-\left(\frac{2}{n+1}\right) M f^{\prime}=0 \\
& {\left[1+\frac{4 R_{d}}{3}\left(1+\left(\theta_{w}-1\right) \theta\right)^{3}\right] \theta^{\prime \prime}+4 R_{d}\left(\theta_{w}-1\right)\left[1+\left(\theta_{w}-1\right) \theta\right]^{2} \theta^{\prime 2}+\operatorname{Pr}\left[f \theta^{\prime}+N b \theta^{\prime} \phi^{\prime}+N t \theta^{\prime 2}\right]=0} \\
& \phi^{\prime \prime}+\frac{1}{2} \operatorname{Le} f \phi^{\prime}+\left(\frac{N t}{N b}\right) \theta^{\prime \prime}=0
\end{aligned}
$$

With boundary conditions

$$
\begin{aligned}
& f(0)=\alpha\left(\frac{1-n}{1+n}\right) \sqrt{\frac{1+n}{2}}, \quad f^{\prime}(0)=1, \quad \theta(0)=1, \quad \phi(0)=1 \quad \text { and } \\
& f^{\prime}(\infty)=0, \quad \theta(\infty)=0, \quad \phi(\infty)=0
\end{aligned}
$$

here primes denote differentiation with respect to $(\zeta)$

\section{Numerical solution}

By assistance of Mathematica program, the Equations (12-14) with the boundary conditions (15) are solved using shooting method as an boundary value problem. In this process, it is necessary to choose a suitable finite value $\zeta \rightarrow \infty$, say $\zeta_{\infty}$. Moreover, it is required the values for $f^{\prime \prime}(0), \theta^{\prime}(0)$, and $\phi^{\prime}(0)$ but no such values are given in the problem. The suitable guess values for $f^{\prime \prime}(0), \theta^{\prime}(0)$, and $\phi^{\prime}(0)$ are chosen and then integration is carried out and compare the calculated values for $f^{\prime \prime}(0), \theta^{\prime}(0)$, and $\phi^{\prime}(0)$ at $\zeta=\zeta_{\max } \cong 100$ with the given boundary conditions $f^{\prime}\left(\zeta_{\infty}\right)=0, \theta\left(\zeta_{\infty}\right)=0, \phi\left(\zeta_{\infty}\right)=0$ and adjust the estimated values, $f^{\prime \prime}(0), \theta^{\prime}(0)$, and $\phi^{\prime}(0)$ using "secant method" to give a better approximation for the solution. By taking a series of values for $f^{\prime \prime}(0), \theta^{\prime}(0)$, and $\phi^{\prime}(0)$ and apply the fourth order classical "Runge-Kutta method" with step-size $\Delta \zeta=0.01$. The above procedure is repeated until we get the converged results within a tolerance limit of $10^{-6}$. To valid the accuracy of this method, the paper of Astrerios [27] has been resolved by this method and the results obtained have been compared with [27] and appears in a good agreement.

Table 1. The values of $-\theta^{\prime}(0)$ at different values of $\theta_{w}$ and $\operatorname{Rd}$ at $\operatorname{Pr}=5.5$

\begin{tabular}{cccc}
\hline$R_{d}$ & $\theta_{w}$ & $\begin{array}{c}\text { Astrerios } \\
{[27]}\end{array}$ & $\begin{array}{c}\text { Present } \\
\text { work }\end{array}$ \\
\hline \multirow{3}{*}{0.6} & 1.10 & 0.5338 & 0.5332 \\
& 1.50 & 0.3069 & 0.3067 \\
& 2.00 & 0.1708 & 0.1706 \\
\hline \multirow{3}{*}{10} & 1.10 & 1.1053 & 1.1050 \\
& 1.50 & 0.9516 & 0.9513 \\
& 2.00 & 0.7358 & 0.7357 \\
\hline
\end{tabular}


Table 2. values of skin friction, Nusselt number and Sherwood number at $\mathrm{M}=0.5, \mathrm{Le}=2, \operatorname{Pr}=6.2, \mathrm{Nt}=\mathrm{Nb}=0.1, \theta_{w}=1.2$ and $\mathrm{R}_{\mathrm{d}}=5$

\begin{tabular}{c|c|c|c|c|c|c|c}
\hline$\alpha$ & $n$ & $f^{\prime \prime}(0)$ & $\theta^{\prime}(0)$ & $\phi^{\prime}(0)$ & $C f x$ & $N u$ & $S h$ \\
\hline \multirow{4}{*}{0.5} & -0.50 & -1.538121 & -1.675650 & 0.418655 & -0.00218 & 596.29 & -148.02 \\
& 1.00 & -1.224745 & -0.292469 & -0.341444 & -0.00346 & 207.48 & 241.44 \\
& 1.50 & -1.182711 & -0.260553 & -0.305144 & -0.00374 & 206.59 & 241.24 \\
\hline \multirow{4}{*}{1} & -0.50 & -2.118823 & -2.808684 & 0.931084 & -0.00300 & 999.49 & -329.19 \\
& 1.00 & -1.224745 & -0.292469 & -0.341444 & -0.00346 & 207.48 & 241.44 \\
& 1.50 & -1.131429 & -0.228266 & -0.267573 & -0.00358 & 180.99 & 211.53 \\
\hline \multirow{4}{*}{2} & -0.50 & -3.413214 & -5.229440 & 1.989354 & -0.00483 & 1860.93 & -703.34 \\
& 1.00 & -1.224745 & -0.292469 & -0.341444 & -0.00346 & 207.48 & 241.44 \\
& 1.50 & -1.036347 & -0.168802 & -0.198050 & -0.00328 & 133.84 & 156.57 \\
\hline
\end{tabular}

Table 3. values of skin friction, Nusselt number and Sherwood number at $\alpha=1, \mathrm{Le}=2, \mathrm{Pr}=6.2, \mathrm{Nt}=\mathrm{Nb}=0.1 \theta_{w}=1.2$ and $\mathrm{R}_{\mathrm{d}}=1$

\begin{tabular}{c|c|c|c|c|c|c|c}
\hline $\mathrm{M}$ & $n$ & $f^{\prime \prime}(0)$ & $\theta^{\prime}(0)$ & $\phi^{\prime}(0)$ & $C f x$ & $N u$ & $S h$ \\
\hline \multirow{4}{*}{0} & -0.50 & -1.166667 & -2.842126 & 0.856815 & -0.00165 & 1011.39 & -302.93 \\
& 1.00 & -1.000000 & -0.324760 & -0.385737 & -0.00283 & 230.39 & 272.76 \\
& 1.50 & -0.957891 & -0.258670 & -0.309025 & -0.00303 & 205.09 & 244.31 \\
\hline \multirow{4}{*}{0.5} & -0.50 & -2.118823 & -2.808684 & 0.931084 & -0.00300 & 997.51 & -329.19 \\
& 1.00 & -1.224745 & -0.292469 & -0.341444 & -0.00346 & 207.48 & 241.44 \\
& 1.50 & -1.131429 & -0.228294 & -0.267769 & -0.00358 & 181.01 & 211.69 \\
\hline \multirow{3}{*}{1} & -0.50 & -2.698243 & -2.790261 & 0.963717 & -0.00382 & 992.93 & -340.73 \\
& 1.00 & -1.414214 & -0.268218 & -0.310326 & -0.00400 & 190.28 & 219.43 \\
& 1.50 & -1.283263 & -0.207393 & -0.252124 & -0.00406 & 164.44 & 199.32 \\
\hline
\end{tabular}

Table 4. values of skin friction, Nusselt number and Sherwood number at $\alpha=1, \mathrm{M}=0.5, \mathrm{Le}=2, \mathrm{Pr}=6.2, \mathrm{Nt}=\mathrm{Nb}=0.1$ and $\theta_{w}=1.2$

\begin{tabular}{c|c|c|c|c|c|c|c}
\hline $\mathrm{R}_{\mathrm{d}}$ & $n$ & $f^{\prime \prime}(0)$ & $\theta^{\prime}(0)$ & $\phi^{\prime}(0)$ & $C f x$ & $N u$ & $S h$ \\
\hline \multirow{4}{*}{0.67} & -0.50 & -2.118823 & -3.570320 & 1.679334 & -0.00300 & 1274.64 & -593.73 \\
& 1.00 & -1.224745 & -0.828226 & 0.070000 & -0.00346 & 588.51 & -49.50 \\
& 1.50 & -1.131429 & -0.538001 & -0.075642 & -0.00358 & 427.19 & 59.80 \\
\hline \multirow{3}{*}{1} & -0.50 & -2.118823 & -2.808684 & 0.931084 & -0.00300 & 999.49 & -329.19 \\
& 1.00 & -1.224745 & -0.709428 & -0.027644 & -0.00346 & 503.28 & 19.55 \\
& 1.50 & -1.131429 & -0.481856 & -0.112276 & -0.00358 & 382.05 & 88.76 \\
\hline \multirow{5}{*}{5} & -0.50 & -2.118823 & -0.843469 & -0.963695 & -0.00300 & 298.60 & 340.72 \\
& 1.00 & -1.224745 & -0.292469 & -0.341444 & -0.00346 & 206.94 & 241.44 \\
& 1.50 & -1.131429 & -0.228279 & -0.267668 & -0.00358 & 180.58 & 211.61 \\
\hline
\end{tabular}


Table 5. values of skin friction, Nusselt number and Sherwood number at $\alpha=1, \mathrm{M}=0.5, \mathrm{Le}=2, \mathrm{Pr}=6.2, \mathrm{Nt}=\mathrm{Nb}=0.1$ and $\mathrm{R}_{\mathrm{d}}=0.8$

\begin{tabular}{c|c|c|c|c|c|c|c}
\hline$\theta_{w}$ & $n$ & $f^{\prime \prime}(0)$ & $\theta^{\prime}(0)$ & $\phi^{\prime}(0)$ & $C f x$ & $N u$ & $S h$ \\
\hline \multirow{4}{*}{1.2} & -0.50 & -2.118823 & -0.843469 & -0.963695 & -0.00300 & 300.54 & 340.72 \\
& 1.00 & -1.224745 & -0.292469 & -0.341444 & -0.00346 & 207.62 & 241.44 \\
& 1.50 & -1.131429 & -0.228279 & -0.267668 & -0.00358 & 181.10 & 211.61 \\
\hline \multirow{1}{*}{1.3} & -0.50 & -2.118823 & -0.684537 & -1.114219 & -0.00300 & 244.43 & 393.94 \\
& 1.00 & -1.224745 & -0.244647 & -0.376534 & -0.00346 & 173.85 & 266.25 \\
& 1.50 & -1.131429 & -0.193244 & -0.290079 & -0.00358 & 153.45 & 229.33 \\
\hline \multirow{1}{*}{1.4} & -0.50 & -2.118823 & -0.562331 & -1.228851 & -0.00300 & 201.28 & 434.46 \\
& 1.00 & -1.224745 & -0.206251 & -0.403629 & -0.00346 & 146.75 & 285.41 \\
& 1.50 & -1.131429 & -0.164541 & -0.307619 & -0.00358 & 130.80 & 243.19 \\
\hline \multirow{1}{*}{1.5} & -0.50 & -2.118823 & -0.467004 & -1.317470 & -0.00300 & 167.63 & 465.80 \\
& 1.00 & -1.224745 & -0.175112 & -0.424861 & -0.00346 & 124.77 & 300.42 \\
& 1.50 & -1.131429 & -0.140860 & -0.321560 & -0.00358 & 112.12 & 254.22 \\
\hline
\end{tabular}

\section{Results}

As mentioned before, the most important application of the Nanofluids is using it as coolants because of its high thermal conductivity, one of these applications is heat treatment process which aim to improve the mechanical properties of the surface by heating and cooling it in a series. The rate of cooling (heat flux) in this process controls the hardness, stiffness, strength, ductility, and surface cracking. So this work concern on this point beside the other physical parameters such as surface shear stress and the mass flux.

\section{1 surface shear stress}

$$
\tau_{w}=\mu\left(\frac{\partial u}{\partial y}\right)_{y=\delta(x+b)^{\frac{1-n}{2}}}=\mu U_{w} \sqrt{\frac{a}{v}\left(\frac{n+1}{2}\right)(x+b)^{n-1}} f^{\prime \prime}(0)
$$

Since the skin friction coefficient given by

$$
C_{f}=\frac{2 \tau_{w}}{\rho U_{w}^{2}} \quad \text { i.e. } \quad 2 \sqrt{\left(\frac{n+1}{2}\right)} f^{\prime \prime}(0)=\sqrt{R_{e}} C_{f x}
$$

5.2 surface heat flux (rate of heat transfer)

$$
q_{w}=\left(q_{r}\right)_{w}-k\left(\frac{\partial T}{\partial y}\right)_{y=\delta(x+b)^{\frac{1-n}{2}}}=-\left[k\left(T_{w}-T_{\infty}\right) \sqrt{\left(\frac{n+1}{2}\right) \frac{a}{v}}(x+b)^{\frac{n-1}{2}}+\frac{4}{3} R_{d} k \mathrm{~T}_{\infty}\left(\theta_{w}-1\right) \theta_{w}^{3}\right] \theta^{\prime}(0)
$$

Since the Nusselt number given by

$$
N u=\frac{(x+b) q_{w}}{k\left(T_{w}-T_{\infty}\right)} \quad \text { i.e. } \quad N u=-\left[\sqrt{\frac{n+1}{2}} \sqrt{R_{e}}+\frac{4 R_{d} \theta_{w}^{3}}{3}\right] \theta^{\prime}(0)
$$


5.3 surface mass flux (rate of mass transfer)

$$
q_{m}=-D_{B}\left(\frac{\partial C}{\partial y}\right)_{y=\delta(x+b)^{\frac{1-n}{2}}}=-D_{B}\left(C_{w}-C_{\infty}\right) \sqrt{\left(\frac{n+1}{2}\right) \frac{a}{v}}(x+b)^{\frac{n-1}{2}} \phi^{\prime}(0)
$$

Since the Sherwood number given by

$$
S h=\frac{(x+b) q_{m}}{D_{B}\left(C_{w}-C_{\infty}\right)} \quad \text { i.e. } \quad \frac{S h}{\sqrt{R_{e}}}=-\sqrt{\frac{n+1}{2}} \phi^{\prime}(0)
$$

\section{Discussions}

This study present the thickness variation as a new and important factor that controls the outer surface shape, type of motion and the behavior of the boundary layer. The outer shape of the surface depends on the value of $n$. such that for $n=1$ (plotted by Dot-Dash line), the study reduced to flat surface with constant thickness $(\delta)$ while for $n<1$ (plotted by solid line), the study deals a surface with increasing thickness. However, for $n>1$ (plotted by Dash line), the study transformed to a surface with decreasing thickness.

Moreover, the value of $n$ controls the boundary layer behavior such that for $n=1$ the boundary condition (15) reduced to $f(0)=0$ which indicates to impermeable surface. While for, $\mathrm{n}<1$ the boundary condition becomes $f(0)>0$ which indicates to suction process. and for $n>1$ the boundary condition becomes $f(0)<0$ which indicates to injection process.

The aim of this section is to discuss the above three cases under the effect of the nonlinear rosseland thermal radiation and magnetic field in presence of Brownian motion and thermophoresis. The surface shear stress, rate of cooling and rate of mass transfer investigated through tables (2-5).

\section{1 influence of surface flatness}

The influence of variation of the surface thickness on the boundary layer behavior appears through the thickness parameter $(\alpha)$. Figures 2,3 and 4 present the velocity, temperature and the concentration profiles as thickness parameter varies. It is observed that increasing of $\alpha$ leads to decreasing of the velocity, temperature and nanoparticles concentration in the case of $n<1$ and the opposite is true for $n>1$ and no effect of thickness parameter on the boundary layer in the case of flat surface $n=0$. Moreover, one can observe that the thermal and concentration boundary layer thickness in the case of $n<1$ is biggest than that in the case of $n>1$. In addition, it is clear that the concentration of the nanoparticles close to the surface in the case $n<1$ is higher than that in the case of $n>1$.

On the other hand, table 2 shows the effect of thickness parameter on the velocity gradient, temperature gradient, and the concentration gradient and the corresponding values of skin friction, Nusselt number and Sherwood number. It noted that the increasing of thickness parameter leads to increasing of all previous physical properties. 
It is worth mentioning that increases the rate of heat transfer from the surface leads to acceleration of cooling process, which has a direct positive effect on surface mechanical properties of the surface such as hardness, stiffness, strength.

\section{2 influence of hydromagnetic flow}

The effect of magnetic field on the boundary layer velocity, temperature, and concentration shown through figures 5,6 and 7. One can observe that the increase of magnetic parameter decrease the velocity and decrease the temperature and nanoparticles concentration. Moreover, it is clear that the effect of magnetic parameter on the temperature and nanoparticles concentration in the case of $n<1$ is very weak. In addition, at the same conditions, the nanoparticles concentration in the case of $n<1$ near the surface increases gradually and then decay to zero rapidly on the contrary of the other cases of $n$-value.

The effect of hydromagnetic flow on the skin friction, Nusselt number and Sherwood number tabulated in table 3. By comparing, one can observe that using hydromagnetic flow as a cooling medium increase skin friction, Sherwood number and decrease Nusselt number. Consequently, the surface shear stress and rate of mass transfer increased and rate of heat transfer decreased by increasing of magnetic parameter $\mathrm{M}$.

\section{3 influence of nonlinear thermal radiation}

The most recent papers investigate the effect of thermal radiation on the boundary layer through the linear Rosseland approximation, which appears in the dimensionless system through the radiation parameter $\left(R_{d}\right)$. One of the paper scopes is to study the effect of the thermal radiation through the non-linear Rosseland approximation which appears in the dimensionless system through the radiation parameter $\left(R_{d}\right)$ and temperature ratio parameter $\left(\theta_{w}\right)$.

The effect of radiation parameter on the boundary layer temperature and concentration plotted through figures 8 and 9 . It is clear that the increase of this parameter increase the boundary layer temperature. In addition, one can observe that the impact of this parameter be more active by increasing of its value. Moreover, the effect of radiation parameter on the nanoparticles concentration is very clear especially in the case of $n>1$ such that the increase of it decrease the concentration near the surface before decaying to zero.

On the other hand, the effect of temperature ratio on the boundary layer temperature and concentration showed by figures 10 and 11 . The figures show that the increase of the temperature ration increase the boundary layer temperature and decrease the concentration of the nanoparticles near the surface. Moreover, it is clear that at a certain zone into the boundary layer the concentration be constant at any value of temperature ratio.

The effect of nonlinear radiation on the skin friction Nusselt number and Sherwood number showed in tables $4 \& 5$. It is clear that the presence of thermal radiation increase the temperature and the concentration gradient at the surface, which affected the Nusselt and Sherwood number by increasing. The same effect on the Sherwood number appears in the presence of temperature ratio parameter and the opposite is true for Nusselt number.

\section{4 influence of Brownian motion}

The random movement of the particles suspended in a fluid (nanoparticles) resulting from their bombardment by the fast moving atoms or molecules in the fluid called the Brownian motion. This motion controls the temperature and the concentration of the particles within the boundary 
layer over the surface. The Brownian motion parameter $\mathrm{Nb}$ is the key of this mechanism in this study such that the increasing of $\mathrm{Nb}$ leads to increasing of the boundary layer temperature and decreasing of the nanoparticles concentration as shown in figures 12 and 13. Moreover, it is clear that the impact of the random moving of particles on the concentration decreases by increase the value of Brownian motion parameter for all values of shape parameter $n$.

\section{5 influence of thermophoresis particle deposition}

Thermophoresis is a phenomenon observed in mixtures of mobile particles where the different particle types exhibit different responses to the force of a temperature gradient. Influence of this phenomenon appears in this study through the thermophoresis parameter $\mathrm{Nt}$ such that increasing this parameter leads to increasing of boundary layer temperature and nanoparticles concentration as shown in figures 14 and 15. In addition, figure 15 show that the effect of this phenomenon on the concentration is more clear in the case of $n>1$.

\section{Conclusion}

This study present a mathematical model of a continuous moving surface with variable thickness embedded into a Nanofluid under the effect of nonlinear thermal radiation and magnetic field. The behavior of the boundary layer under the suggested forces and the influence of these on the heat and mass transfer characteristics and the mechanical properties of the surface were the goal in this study and the following results obtained:

- Thickness parameter $(\alpha)$ and shape parameter $(n)$ both play an important role in the thermal and concentration boundary layer behavior.

- The boundary layer thickness in the case of $n<1$ is bigger than that in the case of $n>1$.

- Hydro-magnetic flow has no strong effect on the boundary layer temperature and concentration in the case of $n<1$.

- The non-linear Rosseland thermal radiation has a clear impact on the thermal and concentration boundary layer.

- The Brownian motion and thermophoresis both have a clear impact on the nanoparticle concentration especially in the case of $n>1$.

- The rate of heat transfer from the surface (Nusselt Number) increases in presence of thickness and radiation parameters and the opposite is true for magnetic and temperature ratio parameters.

- Generally, the rate of heat transfer from the convex outer shape surface $(n<1)$ is higher than that in the case of concave outer shape surface $(n>1)$.

\section{References}

[1] M.E. Ali, Int. J. Heat Mass Flow, 16,280-290,(1995). doi:10.1016/0142-727X(95)00001-7

[2] E.M.A. Elbashbeshy and M.A.A. Bazid, J. phys. D, phys, 33, 2721, (2000). doi:10.1088/0022-3727/33/21/309

[3] E.M.A. Elbashbeshy and M.A.A. Bazid, Appl Math. Coput. 158(3), 799-807, (2004). doi:10.1016/j.amc.2003.08.141 
[4] E.M.A. Elbashbeshy and M.A.A. Bazid, Int. J. Heat Mass Transfer, 43, 3087-2092, (2000). doi:10.1016/S0017-9310(99)00359-2

[5] E.M.A. Elbashbeshy and M.A.A. Bazid, Heat Mass Transfer, 41,1-4,(2004). doi:10.1007/s00231-004-0520-x

[6] E.M.A. Elbashbeshy and M.A.A. Bazid, Appl. Math and Computations. 138(3), 239245,(2003). doi:10.1016/S0096-3003(02)00106-6

[7] R. Nazar, N. Amin, I. Pop and D. Flip. Int. J. Eng. Sci. 42, 1241-1253, (2004). doi:10.1016/j.ijengsci.2003.12.002

[8] A. Ishak, R. Nazar, and I. Pop, Nonlinear Analysis: Real World Application 10, 2909-2913, (2009). doi.:10.1016/j.nonrwa.2008.09.010

[9] K.V. Prasad, D. Pal, P.S. Datti. Commun, Non-Linear Sci. Numer. Simulat.14, 2178-2189, (2009). doi:10.1016/j.cnsns.2008.06.021

[10] K.V. Prasad, K. Vajravelu, P.S. Datti, Int. J. of thermal Sci. 49, 603-610, (2010). doi:10.1016/j.ijthermalsci.2009.08.005

[11] N. Ahmed, S.T. Mohyud-Din, S.M. Hassan. A Numerical Investigation, Aerospace Science \& Technology, 48, 53-60, (2016). doi: 10.1016/j.ast.2015.10.022

[12] U. Kan, N. Ahmed and S.T. Mohyud-Din, Aerospace Science \& Technology, (2015). doi: 10.1016/j.ast.2015.12.009.

[13] U. Kan, N. Ahmed and S.T. Mohyud-Din, Neural Computing and Applications, (2015). doi:10.1007/s00521-016-2187-x

[14] S.U.S. Choi, ASME Fluid Eng. Division, 231, 99-105, (1995).

[15] M. Azizah, A. Syakila, I. Pop, Int. J. Heat and Mass Transfer, 55, 1888-1897, (2012). doi:10.1016/j.ijheatmasstransfer.2011.11.042

[16] P. Rana, and R. Bhargava, Commun Nonlinear Sci Numer, 17, 212-226, (2012). doi:10.1016/j.cnsns.2011.05.009

[17] Aminreza N., Rashid P., and Mohamed G, Int. J. of thermal Sci., 51, 1-9, (2012). doi:10.1016/j.ijthermalsci.2011.11.017

[18] M. Hamad, Int. comm. in heat and mass transfer 38, 487-492, (2011). doi:10.1016/j.icheatmasstransfer.2010.12.042

[19] N.A. Yacob, A. Ishak, R. Nazar, and I. Pop, Nanoscale Research Letters, 6:1-7, (2011). doi:10.1186/1556-276X-6-314

[20] E. M. A. Elbashbeshy, T.G. Emam and M. S. Abdel-wahed, Heat and Mass Transfer, 50(1), 57-64, (2014). doi:10.1007/s00231-013-1224-x

[21] E. M. A. Elbashbeshy, T.G. Emam and M. S. Abdel-wahed, International Journal of Applied Mathematics, 14 (10), 436-442, (2012). 
[22] A. Alsaedi, M. Awais, and T. Hayat, Commun Nonlinear Sci Numer, 17, 4210-4223, (2012). doi:10.1016/j.cnsns.2012.03.008

[23] E. Magyari, A. Pantokratoras, Int Comm. Heat Mass Transfer 38, 554-556, (2011). doi:10.1016/j.icheatmasstransfer.2011.03.006

[24] T.G. Motsumi, O.D. Makinde, Phys Scr 86: 045003, (2012). doi:10.1088/00318949/86/04/045003

[25] F.M. Hady, F.S. Ibrahim, S.M.A. Gaied, M.R. Eid, Nanoscale Res. Letter 7: 229, (2012). doi:10.1186/1556-276X-7-229

[26] E. M. A. Elbashbeshy, T.G. Emam and M. S. Abdel-wahed, Thermal science, 19 (5), 1591-1601, 2015. doi:10.2298/TSCI121007111E

[27] P. Astreios, T. Fang, physica Scripta 87, 015703, 2013. doi:10.1088/00318949/87/01/015703

[28] S.T. Mohyud-Din and S.I. Khan, Aerospace Science and Technology, 48, 186-192, (2016). doi:10.1016/j.ast.2015.10.019

[29] U. Khan, N. Ahmed and S.T. Mohyud-Din, A numerical study; Neural Computing and Applications, (2015), doi:10.1007/s00521-015-2035-4.

[30] M.S. Abdel-wahed and T.G. Emam, Thermal Sciences, (2016), doi: 10.2298/TSCI160312218A

[31] M.S. Abdel-wahed and M. Akl, AIP Advances 6, (2016), doi: 10.1063/1.4962961.

[32] N. Anbuchezhian, K. Srinivasan, K. Chandrasekaran, and R. Kandasamy, Applied Mathematics and Mechanics 33, 765-780, (2012). doi:10.1007/s10483-012-1585-8

[33] R. Kandasamy, I. Muhamin, R. Mohamad, Int. J. Mech Sci 70: 146-154, (2013). doi:10.1016/j.ijmecsci.2013.03.007

[34] T. Fang, J. Zhang, Y. Zhong, Applied Mathematics and Computation 218, 7241-7252, (2012). doi:10.1016/j.amc.2011.12.094

[35] E.M.A Elbashbeshy, T.G. Emam, and M. S. Abdel-wahed, Can. J. Phys. 91, 699-708, (2013). doi:10.1139/cjp-2013-0168

[36] M. S. Abdel-wahed, E.M.A Elbashbeshy and T.G. Emam, Applied Mathematics and computation. 254, 49-62, (2015). doi:10.1016/j.amc.2014.12.087 


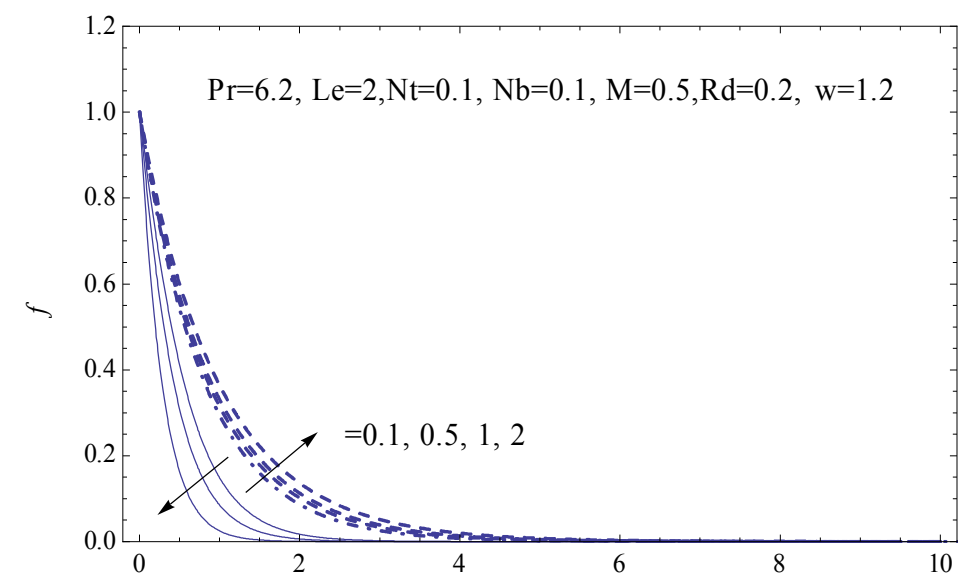

Fig (2): The velocity profiles with increasing of thickness parameter $(\alpha)$.

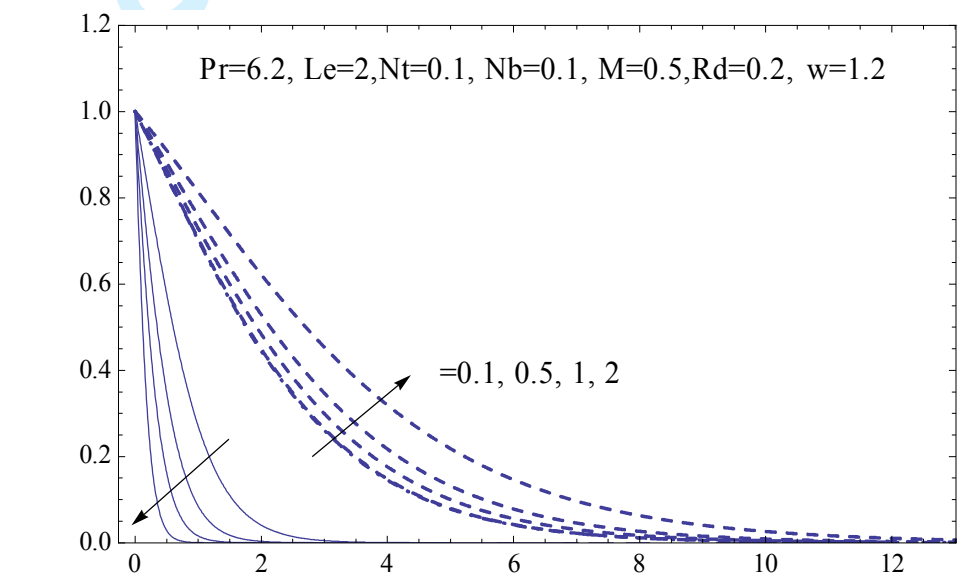

Fig (3): The temperature profiles with increasing of thickness parameter $(\alpha)$.

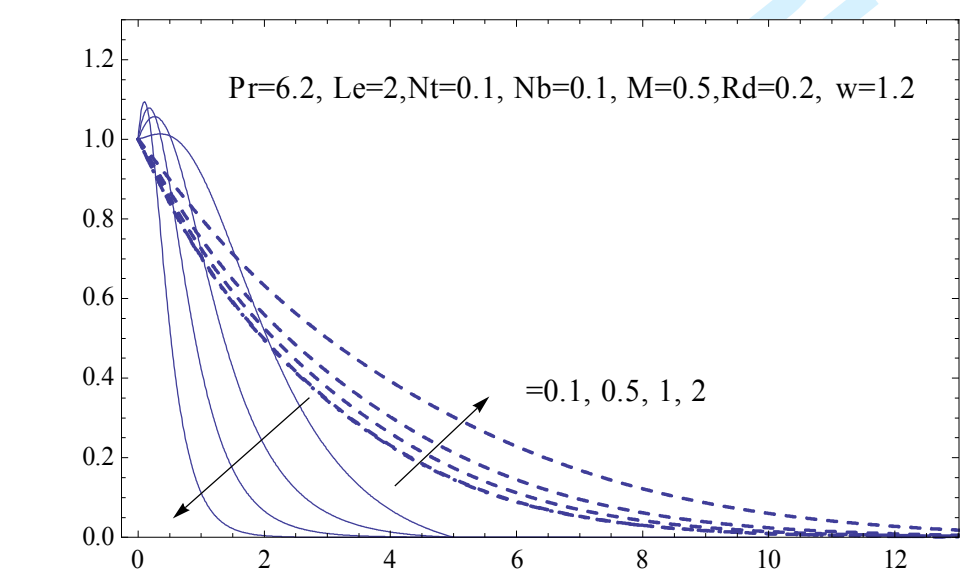

Fig (4): The concentration profiles with increasing of thickness parameter $(\alpha)$. 


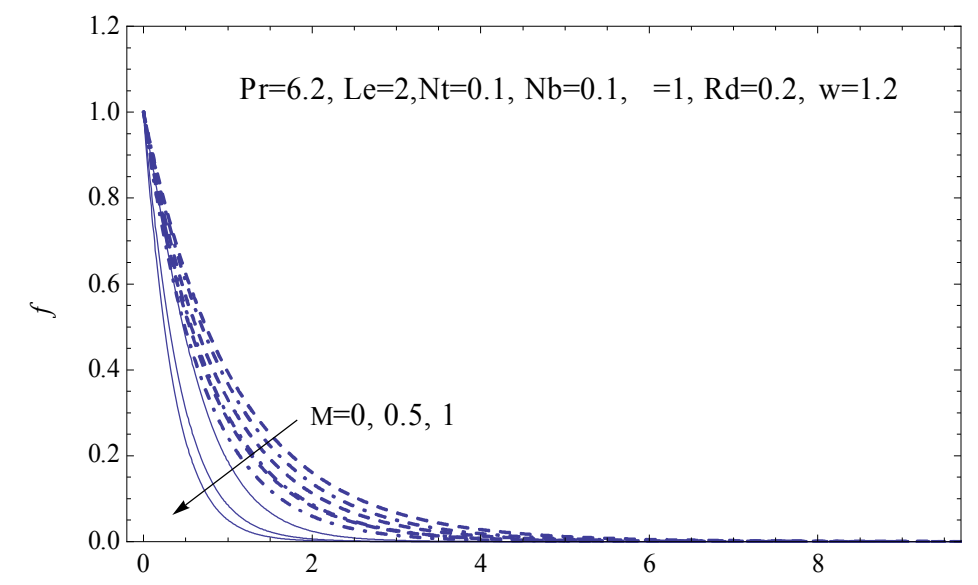

Fig (5): The velocity profiles with increasing of magnetic parameter (M).

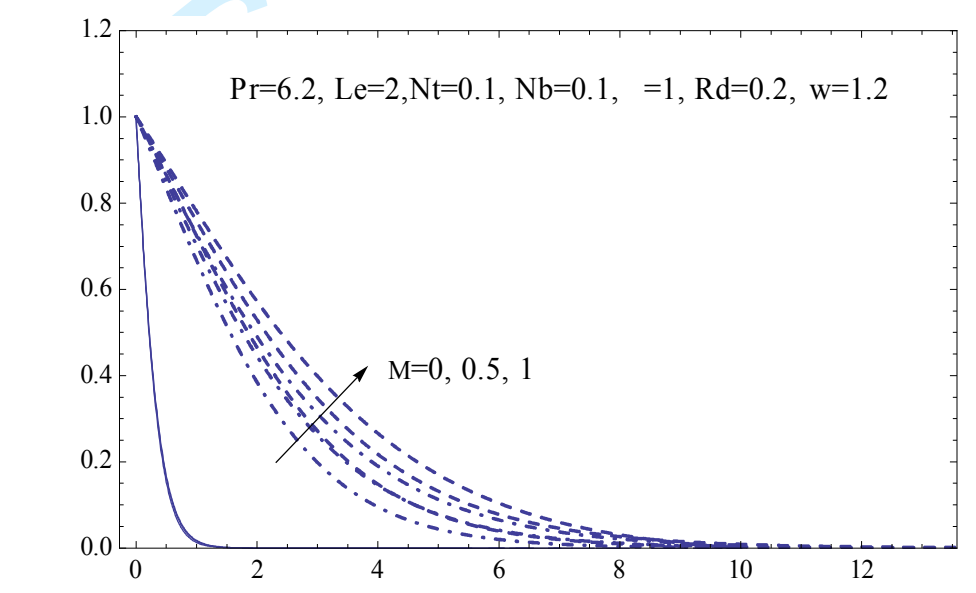

Fig (6): The temperature profiles with increasing of magnetic parameter (M).

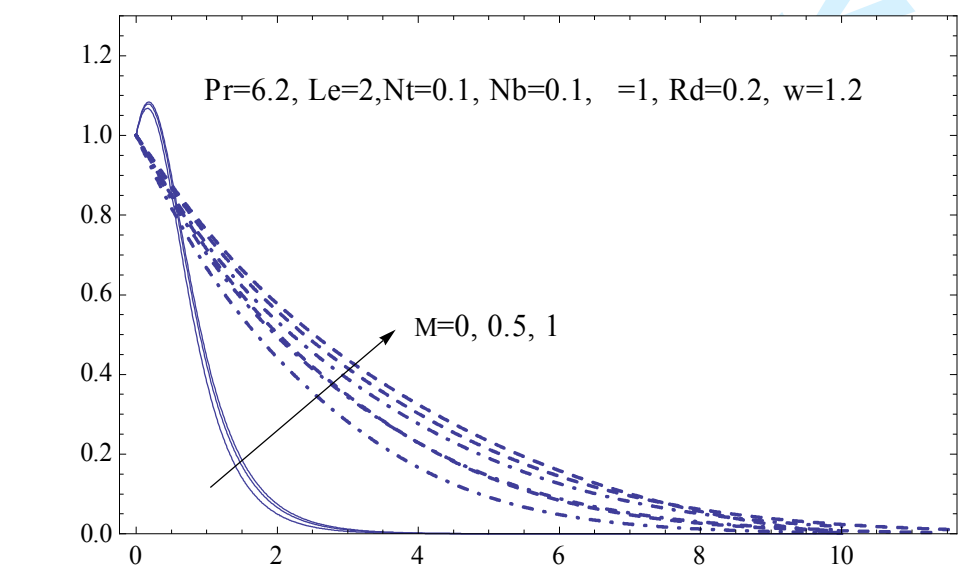

Fig (7): The concentration profiles with increasing of magnetic parameter (M). 


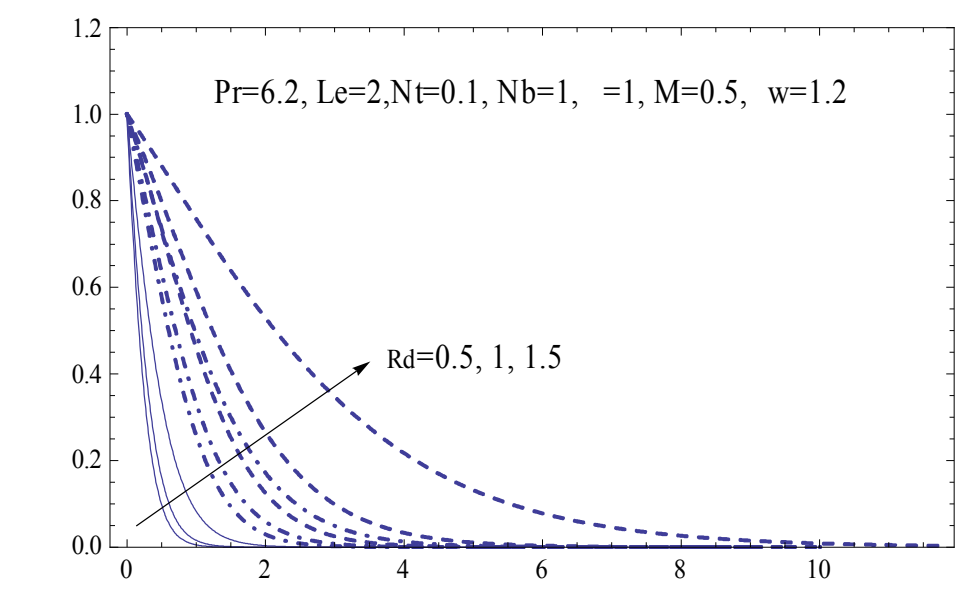

Fig (8): The temperature profiles with increasing of radiation parameter $\left(R_{d}\right)$.

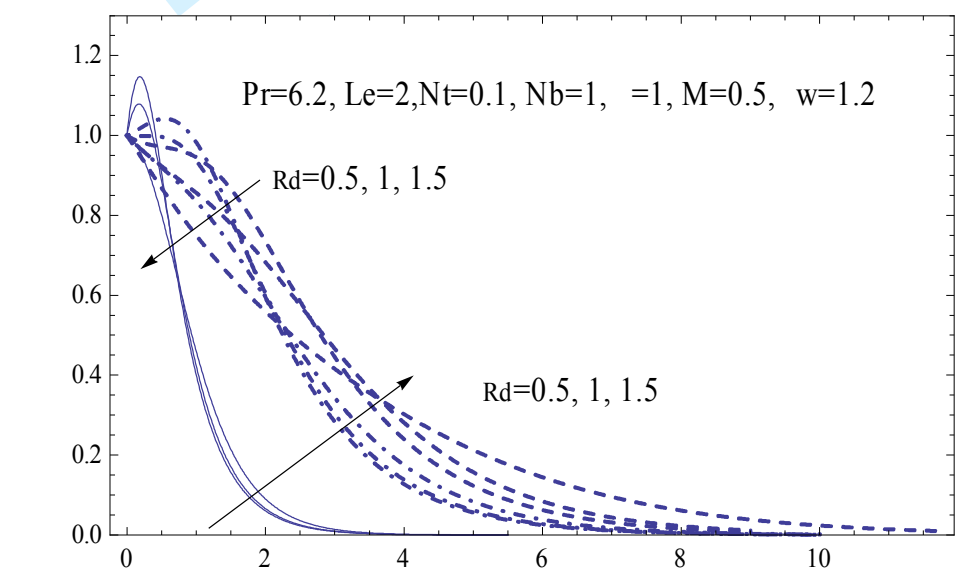

Fig (9): The concentration profiles with increasing of radiation parameter $\left(R_{d}\right)$.

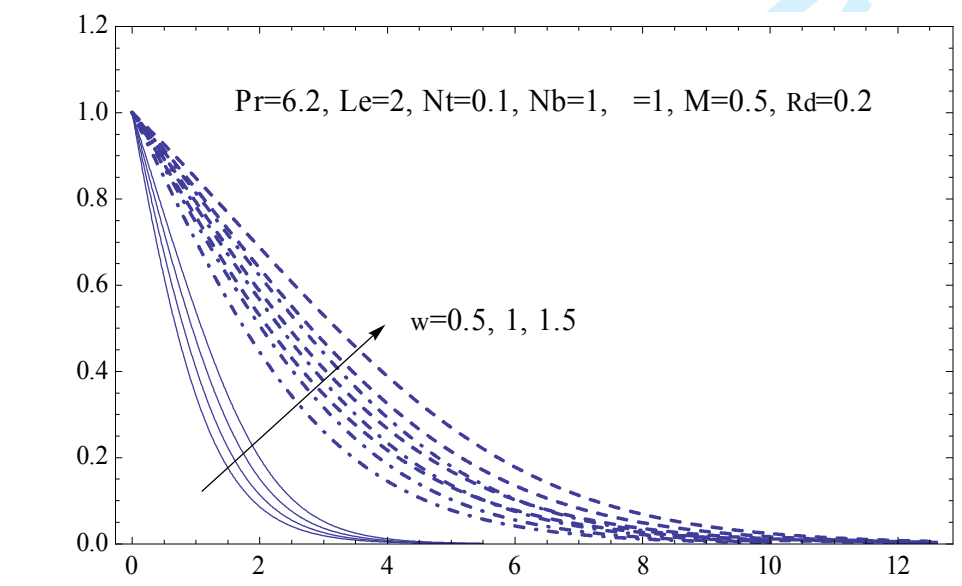

Fig (10): The temperature profiles with increasing of temperature ratio $\left(\theta_{w}\right)$. 


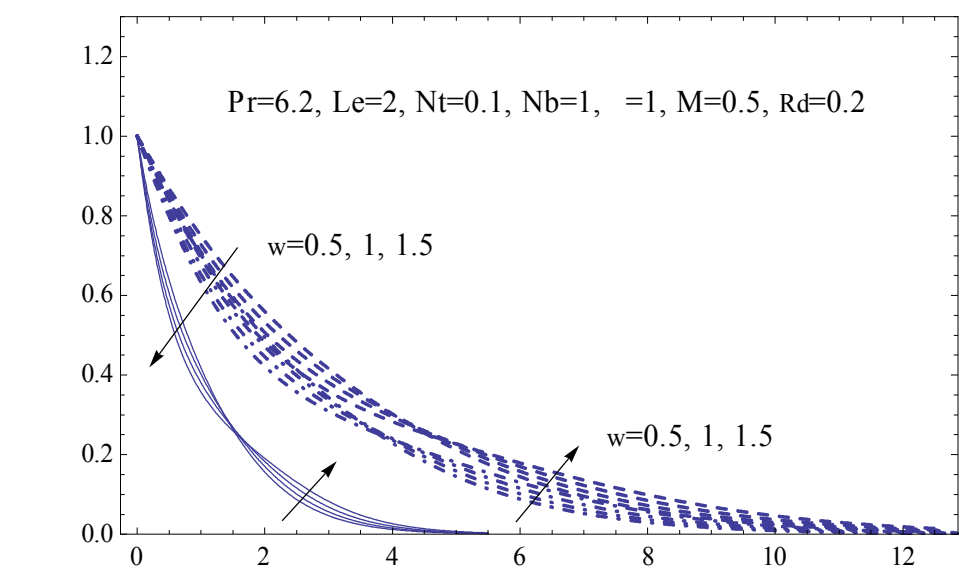

Fig (11): The concentration profiles with increasing of temperature ratio $\left(\theta_{w}\right)$.

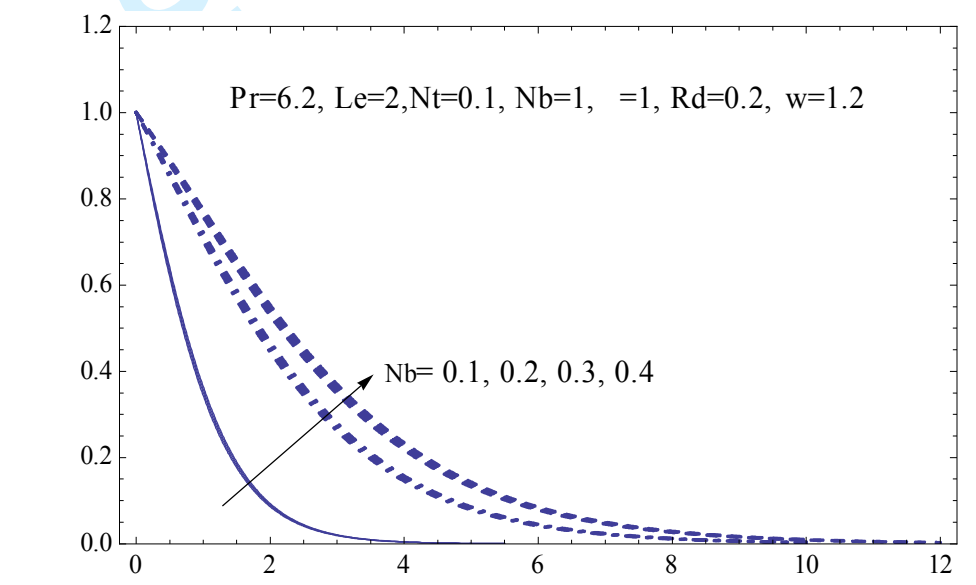

Fig (12): The temperature profiles with increasing of Brownian parameter $\mathrm{Nb}$.

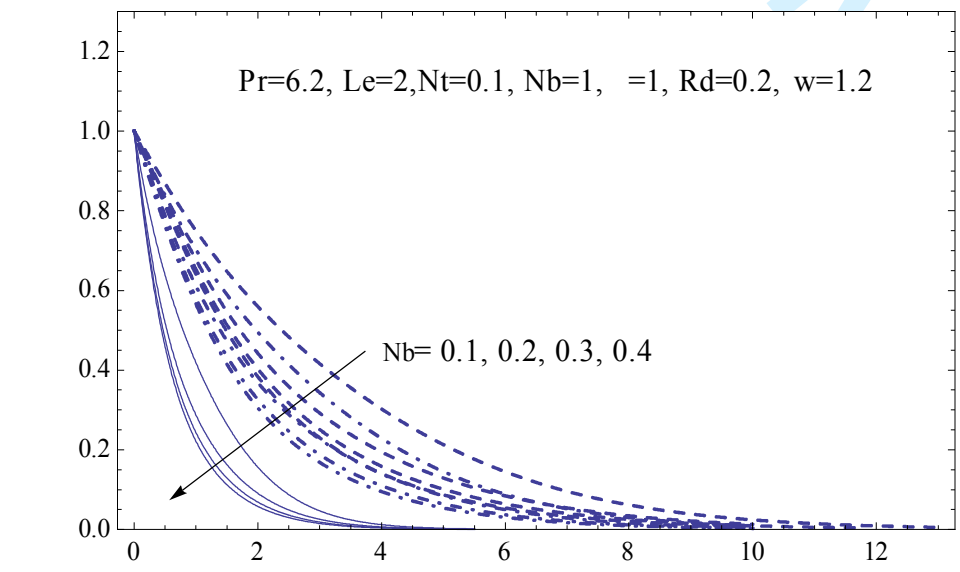

Fig (13): The concentration profiles with increasing of Brownian parameter $\mathrm{Nb}$. 


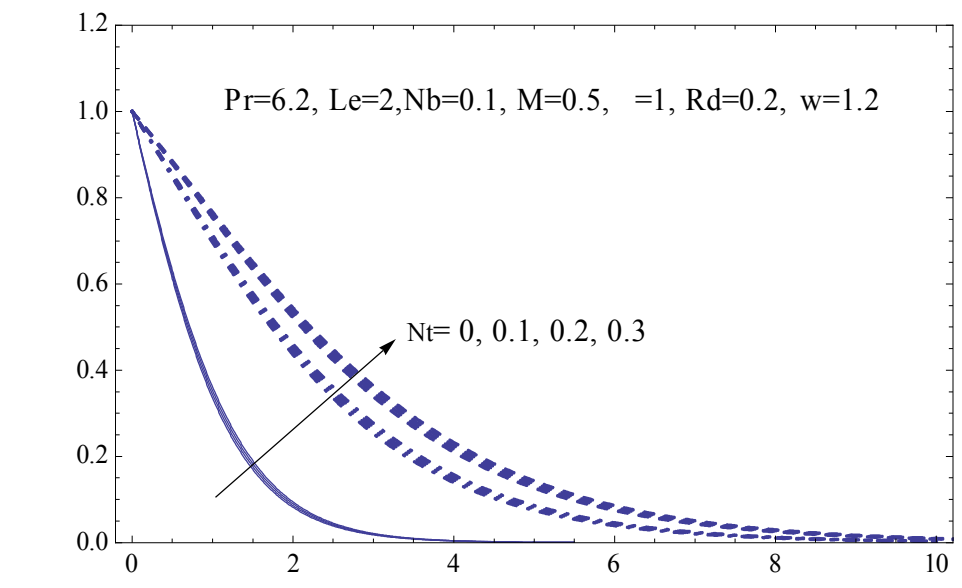

Fig (14): The temperature profiles with increasing of Thermophoresis parameter Nt.

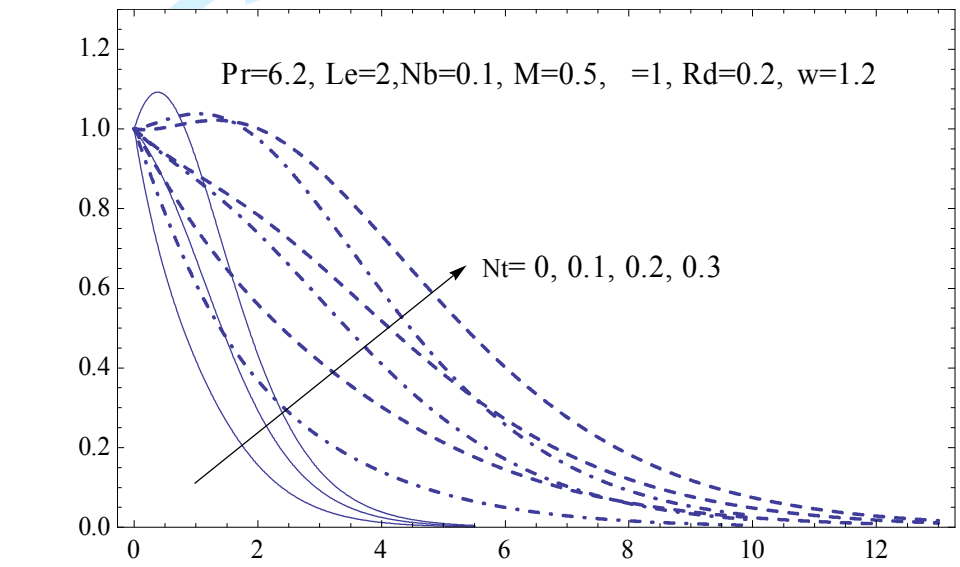

Fig (15): The concentration profiles with increasing of Thermophoresis parameter Nt.

\section{List of Symbols}

$u, v \quad$ velocity components in the $x$ and $y$ directions, respectively

$v \quad$ kinematic viscosity

$\rho \quad$ Density of the base fluid,

$\sigma \quad$ electrical conductivity,

$B(x) \quad$ strength of the magnetic field

$\alpha^{\times} \quad$ thermal diffusion,

$D_{B} \quad$ Brownian diffusion coefficient,

$D_{T} \quad$ Thermophoretic diffusion coefficient

$\rho^{*} \quad$ Boltzmann constant,

$\alpha^{*} \quad$ Rosseland mean absorpation

$b$ constant

$\phi(\eta)$ Dimensionless concentration 
$\eta \quad$ similarity variable

$\psi \quad$ stream function

$\alpha \quad$ thickness parameter $\alpha=\delta \sqrt{\frac{a}{v}}$

$\theta_{w} \quad$ temperature ratio $\theta_{w}=\frac{T_{w}}{T_{\infty}}$

$\operatorname{Pr} \quad$ prandtl number $\operatorname{Pr}=\frac{v}{\alpha}$

Le lewis number, $L e=\frac{v}{D_{B}}$

M magnetic field parameter, $M=\frac{\beta_{0}^{2} \sigma}{a \rho}$

$\mathrm{Nb} \quad$ brownian motion parameter, $N b=\frac{\tau D_{B}}{v}\left(C_{w}-C_{\infty}\right)$

$\mathrm{Nt} \quad$ thermophoresis parameter, $N t=\frac{\tau D_{t}}{v T_{\infty}}\left(T_{w}-T_{\infty}\right)$

$R_{d} \quad$ radiation parameter, $R_{d}=\frac{4 \sigma^{*} T_{\infty}^{3}}{k \alpha^{*}}$

$\tau$ ratio between the effective heat capacity of the nanoparticles and heat capacity of the fliud, $\tau=\frac{(\rho C p)_{p}}{(\rho C p)_{f}}$ 